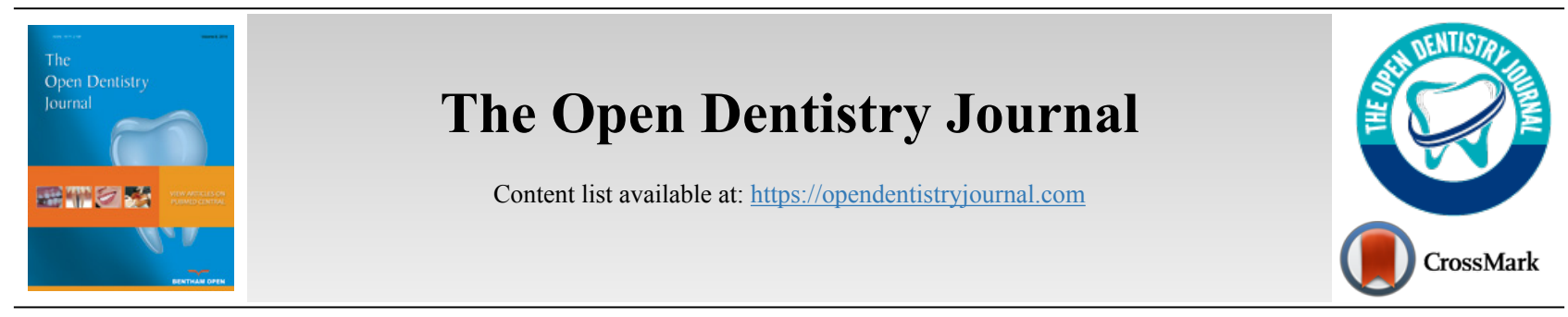

RESEARCH ARTICLE

\title{
Sealant Utilization and its Influence on Caries Reduction in First Permanent Molars in Saudi Female School Children
}

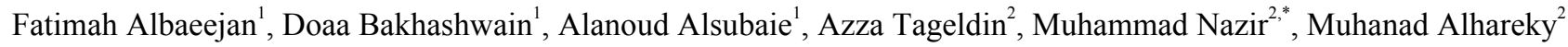 \\ and Jehan AlHumaid ${ }^{2}$
}

${ }^{1}$ College of Dentistry, Imam Abdulrahman Bin Faisal University, Dammam, Saudi Arabia

${ }^{2}$ Department of Preventive Dental Sciences, College of Dentistry Imam Abdulrahman Bin Faisal University, Dammam, Saudi Arabia

\begin{abstract}
:
Purpose:

This study aimed to assess the utilization of fissure sealants and their influence on caries reduction in first permanent molars (FPMs) among 6-9 years old female schoolchildren in Dammam, Eastern Province of Saudi Arabia.

Materials and Methods:

First to fourth grade female children from public schools in Dammam participated in this cross-sectional study. Dental caries and fissure sealants in FPMs were examined clinically using the World Health Organization guidelines. In addition, the parents of the participants responded to a selfreported questionnaire.

\section{Results:}

The study analyzed the data of 449 children. Almost $44.3 \%$ of the participants had at least one FPM affected with caries. There were $8.7 \%$ of the participants who had fissure sealants in at least one FPM, and out of these, only $2.2 \%$ had four FPMs filled with sealants. A significantly greater proportion of participants with sealed FPMs had no caries than the lower proportion of participants without sealants who had caries $(\mathrm{P}=<0.05)$. The use of sealants increased significantly from first grade $(10.3 \%)$ to second grade $(30.8 \%)$, third grade $(38.5 \%)$, and fourth grade $(20.5 \%)(\mathrm{P}=0.006)$. High monthly family income $(\mathrm{P}=0.047)$ and having insurance $(\mathrm{P}=0.017)$ were significantly associated with increased sealant application. Nearly $21.9 \%$ of participants' parents were aware of caries protective effects of dental sealants.

Conclusion:

The application of sealants was significantly associated with reduced caries in FPMs. Class year, monthly family income, and insurance were significantly associated with having sealants. Caries prevention programs for children should incorporate sealant application.
\end{abstract}

Keywords: Sealants, Caries, First permanent molars, Prevention, Awareness, School children.

\begin{tabular}{l|l|l|l} 
Article History & Received: March 28, 2021 & Revised: August 7, 2021 & Accepted: August 21, 2021
\end{tabular}

\section{INTRODUCTION}

Dental caries is a major public health problem as it affected 2.4 billion people globally in 2010 [1]. It also affects the cognitive, emotional, social, and physical development of children [2]. The impairment of chewing, speech, smiling, and sleep can occur because of caries, which can result in poor oral health-related quality of life in children [3]. According to the World Health Organization (WHO), dental caries is the fourth most expensive chronic condition to treat [4]. The cost of caries treatment in children in Saudi Arabia in 2010 was estimated to range from 2.3 to 5.8 billion Saudi Riyals [5].

\footnotetext{
* Address correspondence to this author at the Department of Preventive Dental Sciences, College of Dentistry, Imam Abdulrahman Bin Faisal University, Dammam, Saudi Arabia; E-mail: manazir@iau.edu.sa
}

First permanent molars (FPMs) are predisposed to carious attacks due to their early eruption and anatomical features, in addition to other factors. Pits and fissures in FPMs can retain food debris, impair good oral hygiene, harbor bacterial flora, increase the accumulation of plaque, and promote caries formation [6]. Literature indicates that FPMs have the highest prevalence of dental caries [7]. A recent study involving male school children from Dammam showed that $50.4 \%$ of FPMs had caries which was the highest among all permanent teeth [8].

Fissure sealants are safe and provide the most effective method to reduce caries in at-risk populations. The application of fissure sealants effectively prevents caries and helps to arrest incipient carious lesions [9]. A review of 23 studies suggested 
that the individuals with sealants in permanent molars had a significantly lower likelihood of developing caries than those without sealants [10]. Caries reduction in permanent teeth in children and adolescents by $11 \%-51 \%$ can be achieved by sealants over a period of two years [11]. Sealant application prevents the formation of dental plaque and the development of caries. Hence, it is suggested that sealants should be part of the management of early carious lesions located in the pits and fissures of posterior teeth [12].

In Germany, a study on 12 years old children showed that the mean number of teeth with fissure sealant per child was 1.99 , and the use of fissure sealants was associated with the increased proportion of children without caries [13]. Similar findings were reported in Greek and Portuguese children [6, 14]. In Riyadh, at least one fissure sealant was found in $1.3 \%$ of 6-9 years old Saudi female children, and it was found that a higher proportion of mandibular (33\%) than maxillary (18.2\%) FPMs had caries [15]. Another study from Riyadh also reported low utilization of sealants and a high prevalence of caries in 6-9 years old Saudi male children [16].

Fissure sealants are effective, affordable, and highly recommended for the prevention of dental caries [9 - 11]. However, there are reports about the underutilization of fissure sealants by dentists $[17,18]$. Parents of children also demonstrate low knowledge regarding the effectiveness of sealant against caries $[19,20]$. There is limited evidence about the prevalence of dental caries and the presence of fissure sealants in FPMs in schoolchildren in the Eastern Province of Saudi Arabia. Therefore, the study aims to assess the prevalence of fissure sealants and dental caries in FPMs among female school children of 6-9 years old in the Eastern province of Saudi Arabia. The study provided important data that can be used to promote the application of fissure sealants and the prevention of caries in children.

\section{MATERIALS AND METHODS}

This cross-sectional study was conducted in female primary public schools in Dammam, Eastern Province, Saudi Arabia (September, 2019 till March, 2020). Children of first, second, third, and fourth grade (ages 6-9 years old) were included in the study. A sample of 567 students was calculated based on the estimated population, anticipated \% frequency, confidence limit, and design effect. Four schools were randomly selected by the Ministry of Education in Dammam. The consent forms were sent to the parents of school children, and children who provided written informed consent were eligible to participate in the study.

Three researchers conducted the clinical examination for caries and fissure sealants. To evaluate the inter-and intraexaminer reproducibility, Kappa statics ( $>80$ ) were used. The assessment was done by re-examining 6 children a week before starting the data collection. The clinical examination of children took place in a classroom, under adequate natural daylight, taking into consideration infection control measures. Only FPMs were examined using a disposable mouth mirror and a probe. The examination included FPMs with the exposed occlusal surfaces. Partially erupted or unerupted FPMs were excluded from the study. According to the World Health Organization's (WHO) diagnostic criteria for oral health survey, dental caries was evaluated and marked regardless of the caries stage [21]. No radiographs were used for the evaluation of dental caries. The recording of fissure sealants was done on FPMs regardless of their condition and whether they were intact or partially lost.

A self-administered questionnaire was used for the parents in the study. The questionnaire can be broadly divided into three sections. The first section included the demographic profile of study participants such as age, class year, parental education level, and monthly family income. The WHO's oral health survey for children was included in the second section. The responses about the knowledge and attitude of parents towards fissure sealants were sought in the third section of the questionnaire. There were 11 questions about the knowledge and attitude about fissure sealants derived from valid and reliable questionnaires used in previous studies [19, 20, 22, 23]. The content of the questionnaire was assessed in several meetings to ensure its validity. Arabic translation of the questionnaire was done, and finally, its pretesting was conducted to identify potential areas of improvement.

Ethical approval of the study (IRB 2020-2-068) was obtained from the Deanship of Scientific Research at Imam Abdulrahman Bin Faisal University, Dammam. Official permission to collect data was received from the administration of selected schools. In addition to the consent of parents, the ascent from children was obtained prior to the oral examination. The confidentiality and privacy of the data were maintained. The study was conducted in accordance with the Declaration of Helsinki.

Data were entered in Microsoft Excel's sheet, and statistical analysis was performed using SPSS software (IBM SPSS Statistics for Windows, version 22.0. Armonk, NY: IBM Corp). Descriptive statistics included means, standard deviations, frequencies, and percentages. The Chi-square test was used for categorical variables. A p-value of $<0.05$ was considered statistically significant.

\section{RESULTS}

The data of 449 children were included in the analysis, and the response rate of the study was $79.2 \%$. More than half of the participants had college/university-educated parents. Most participants belonged to the middle-income class and had no insurance. The demographic characteristics of the participants are summarized in Table 1. Fig. (1) shows the prevalence of caries and fissure sealants in children. Nearly $44.3 \%$ of children had at least one FPM affected with caries, and only $8.7 \%$ of the children had fissure sealants in at least one FPM. Among participants affected with carious FPMs, $13.4 \%$ of the participants had caries in all four FPMs while 7.3\% had three carious FPMs, $12 \%$ had two carious FPMs, and $11.4 \%$ had one carious FPM. On the other hand, only $2.2 \%$ of participants had four FPMs filled with sealants, and $4.2 \%$ had sealants applied to one FPM (Fig. 2). 
Table 1. Characteristics of study participants.

\begin{tabular}{|c|c|c|}
\hline Variables & N (449) & Percentages \\
\hline \multicolumn{3}{|l|}{ Class year } \\
\hline First grade & 126 & 28.1 \\
\hline Second grade & 95 & 21.2 \\
\hline Third grade & 101 & 22.5 \\
\hline Fourth grade & 127 & 28.3 \\
\hline \multicolumn{3}{|l|}{ Father's education } \\
\hline No school education & 5 & 1.1 \\
\hline School education & 190 & 42.3 \\
\hline College/University education & 254 & 56.6 \\
\hline \multicolumn{3}{|l|}{ Mother's education } \\
\hline No school education & 6 & 1.3 \\
\hline School education & 206 & 45.9 \\
\hline College/University education & 237 & 52.8 \\
\hline \multicolumn{3}{|l|}{ Monthly Family Income ( $\mathrm{N}=429)$} \\
\hline Low: less than $5000 \mathrm{SAR} / \mathrm{month}$ & 106 & 24.7 \\
\hline Middle: 5001-20000 SAR/month & 272 & 63.4 \\
\hline High: $20000 \mathrm{SAR} / \mathrm{month}$ and above & 51 & 11.9 \\
\hline \multicolumn{3}{|l|}{ Insurance $(\mathrm{N}=414)$} \\
\hline Yes & 164 & 39.6 \\
\hline No & 250 & 60.4 \\
\hline
\end{tabular}

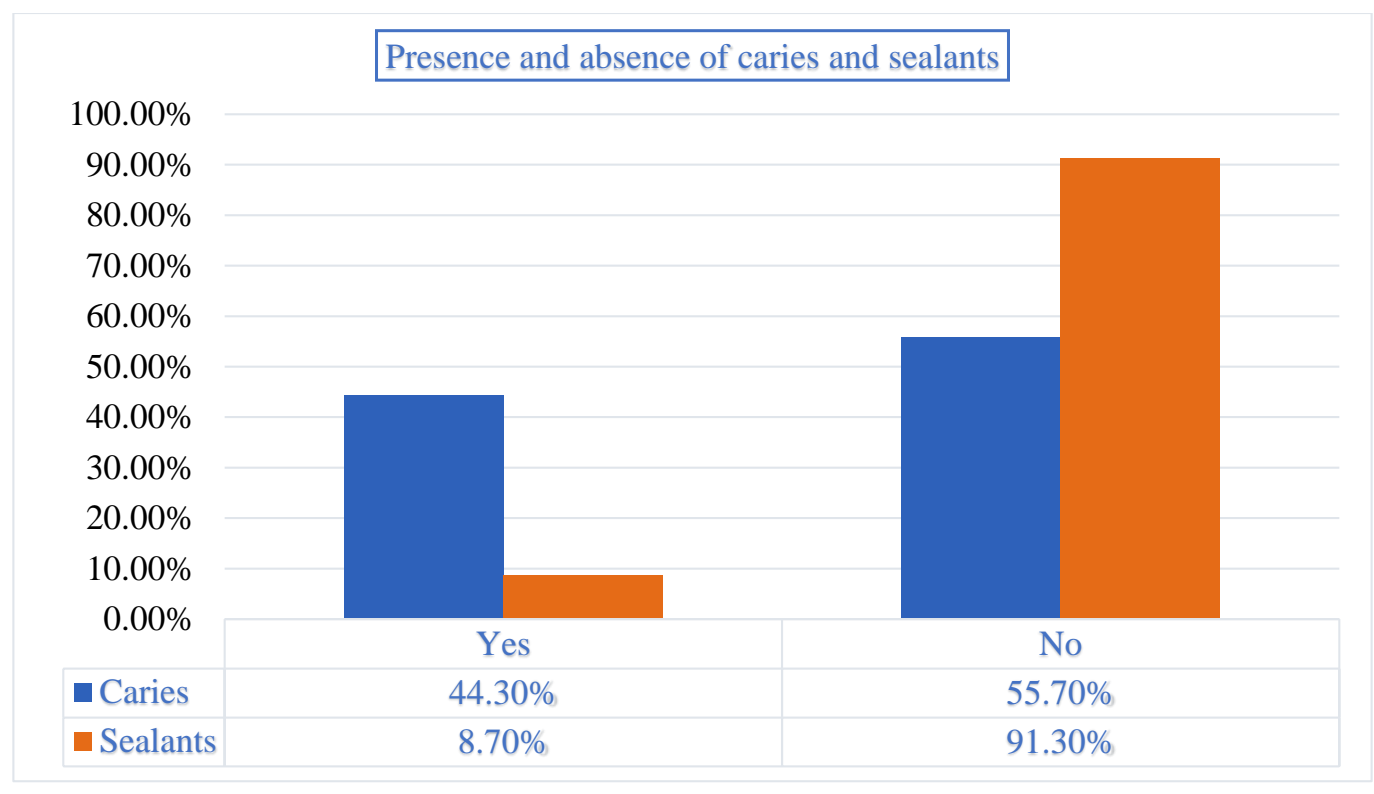

Fig. (1). Presence and absence of caries and fissure sealants among study participants.

Table 2 shows the prevalence of caries and sealants in individual FPM among study participants. Nearly one-quarter of participants (32.1\%) had mandibular left first molar affected with caries which was the most common carious FPM. This was followed by the mandibular right first molar (29.2\%) and maxillary left first molar (25.6\%). Maxillary right first molar was the least affected with caries (24.5\%) in this sample of children. Although the prevalence of fissure sealants in FPMs was low, the mandibular right first molar was the most common FPM filled with sealants (6.2\%). Some $4.7 \%$ of the participants had mandibular left first molars filled with sealants, and only $3.3 \%$ had sealants in maxillary left first molars. 


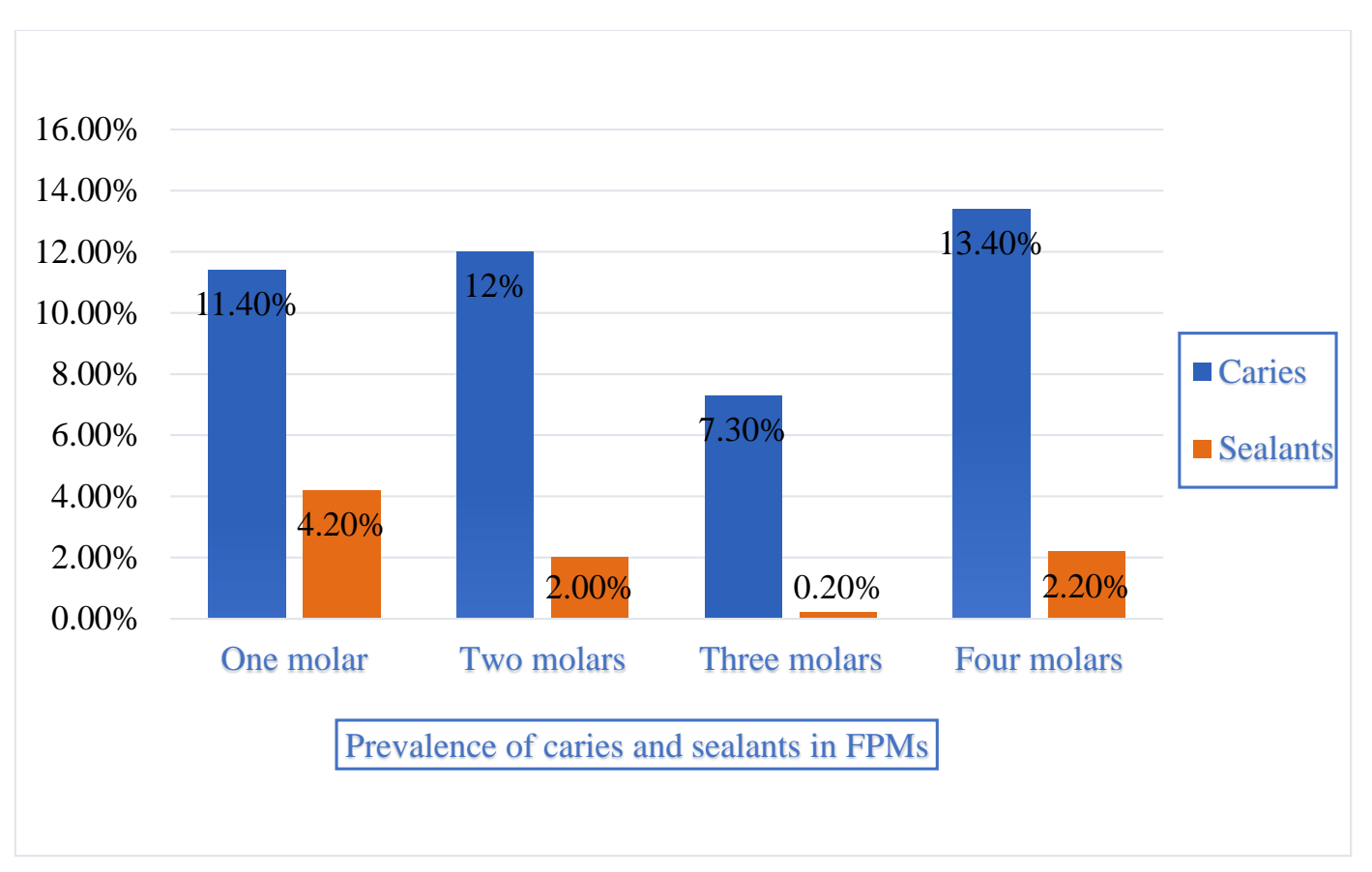

Fig. (2). Prevalence of caries and fissure sealants in PFM teeth among study participants.

Table 2. Prevalence of caries and fissure sealants in FPMs among participants.

\begin{tabular}{|c|c|c|c|c|}
\hline \multirow{2}{*}{ First Permanent Molars } & \multicolumn{2}{|c|}{ Prevalence of Caries } & \multicolumn{2}{c|}{ Prevalence of Sealants } \\
\cline { 2 - 5 } & $\mathbf{N}$ & Percentage & N & \multicolumn{2}{c|}{ Percentage } \\
\hline Maxillary right first molar & & & & 3.6 \\
\hline Yes & 110 & 24.5 & 16 & 96.4 \\
\hline No & 339 & 75.5 & 433 & 3.3 \\
\hline Maxillary center first molar & & & & 96.7 \\
\hline No & 115 & 25.6 & 15 & \\
\hline Mandibular center first molar & 334 & 74.4 & 434 & 4.7 \\
\hline Yes & & & & 95.3 \\
\hline No & 144 & 32.1 & 21 & \\
\hline Yes & 305 & 67.9 & 428 & \\
\hline No & & & & \\
\hline
\end{tabular}

The analysis of data about the association between sealants and caries in individual FPM is presented in Table 3. The greater proportion of participants with maxillary right first molars filled with sealants $(93.8 \%)$ had no caries compared to the lower proportion $(6.3 \%)$ of participants who had caries (P
0.084). Among participants with mandibular right first molar, a significantly higher percentage of participants with sealants had no carious lesion (96.4\%) compared to $3.6 \%$ of those with sealants and caries ( $P$ 0.002). Overall, the application of sealants was associated with reduced caries in FPMs.

Table 3. Association between fissure sealants and caries in each FPMs among participants.

\begin{tabular}{|c|c|c|c|}
\hline Sealants & \multicolumn{2}{|c|}{$\begin{array}{c}\text { Caries in the maxillary right first molar } \\
\text { No } N(\%) \text { Yes } N(\%)\end{array}$} & P-value \\
\hline $\begin{array}{c}\text { Sealants in the maxillary right first molar } \\
\text { Yes } \\
\text { No }\end{array}$ & $\begin{array}{c}15(93.8) \\
324(74.8)\end{array}$ & $\begin{array}{c}1(6.3) \\
109(25.2)\end{array}$ & 0.084 \\
\hline
\end{tabular}




\begin{tabular}{|c|c|c|c|}
\hline Sealants & \multicolumn{2}{|c|}{$\begin{array}{l}\text { Caries in the maxillary right first molar } \\
\text { No N(\%) Yes } \mathrm{N}(\%)\end{array}$} & P-value \\
\hline $\begin{array}{l}\text { Sealants in the maxillary center first molar } \\
\qquad \begin{array}{c}\text { Yes } \\
\text { No }\end{array}\end{array}$ & $\begin{array}{c}15(100) \\
319(73.5)\end{array}$ & $\begin{array}{c}0(0) \\
115(26.5)\end{array}$ & $0.011^{*}$ \\
\hline & \multicolumn{2}{|c|}{$\begin{array}{l}\text { Caries in the mandibular center first molar } \\
\qquad \text { No } N(\%) \text { Yes } N(\%)\end{array}$} & \\
\hline $\begin{array}{l}\text { Sealants in the mandibular center first molar } \\
\text { Yes } \\
\text { No }\end{array}$ & $\begin{array}{c}21(100) \\
284(66.4)\end{array}$ & $\begin{array}{c}0(0) \\
144(33.6)\end{array}$ & 0.001 \\
\hline & \multicolumn{2}{|c|}{$\begin{array}{c}\text { Caries in the mandibular right first molar } \\
\text { No } N(\%) \text { Yes } N(\%)\end{array}$} & \\
\hline $\begin{array}{c}\text { Sealants in the mandibular right first molar } \\
\text { Yes } \\
\text { No }\end{array}$ & $\begin{array}{c}27(96.4) \\
291(69.1)\end{array}$ & $\begin{array}{c}1(3.6) \\
130(30.9)\end{array}$ & 0.002 \\
\hline
\end{tabular}

* Fisher exact test

Table 4 shows the results of the association between having sealant in at least one FPM and sociodemographic factors among study participants. The study found a statistically significant association between having sealants and class year (P 0.006). The use of sealants increased significantly from $10.3 \%$ of children from first grade to $20.5 \%$ in fourth grade. Similarly, a significant association was observed between having sealants and monthly family income, and 8.3\% of participants who had sealants were from the low-income group than $80.6 \%$ of those from the middle-income group and $11.1 \%$ from the high-income group ( $P$ 0.047). Regarding insurance, a significantly higher proportion of participants with sealants $(58.8 \%)$ had insurance compared to a lower proportion $(41.2 \%)$ of participants with sealants without insurance (P 0.017). Fig. (3) shows the awareness of parents about fissure sealants. Only less than one-quarter of parents $(21.9 \%)$ were aware of caries protective effects of dental sealants. Nearly $27.6 \%$ believed that sealants facilitate tooth brushing.

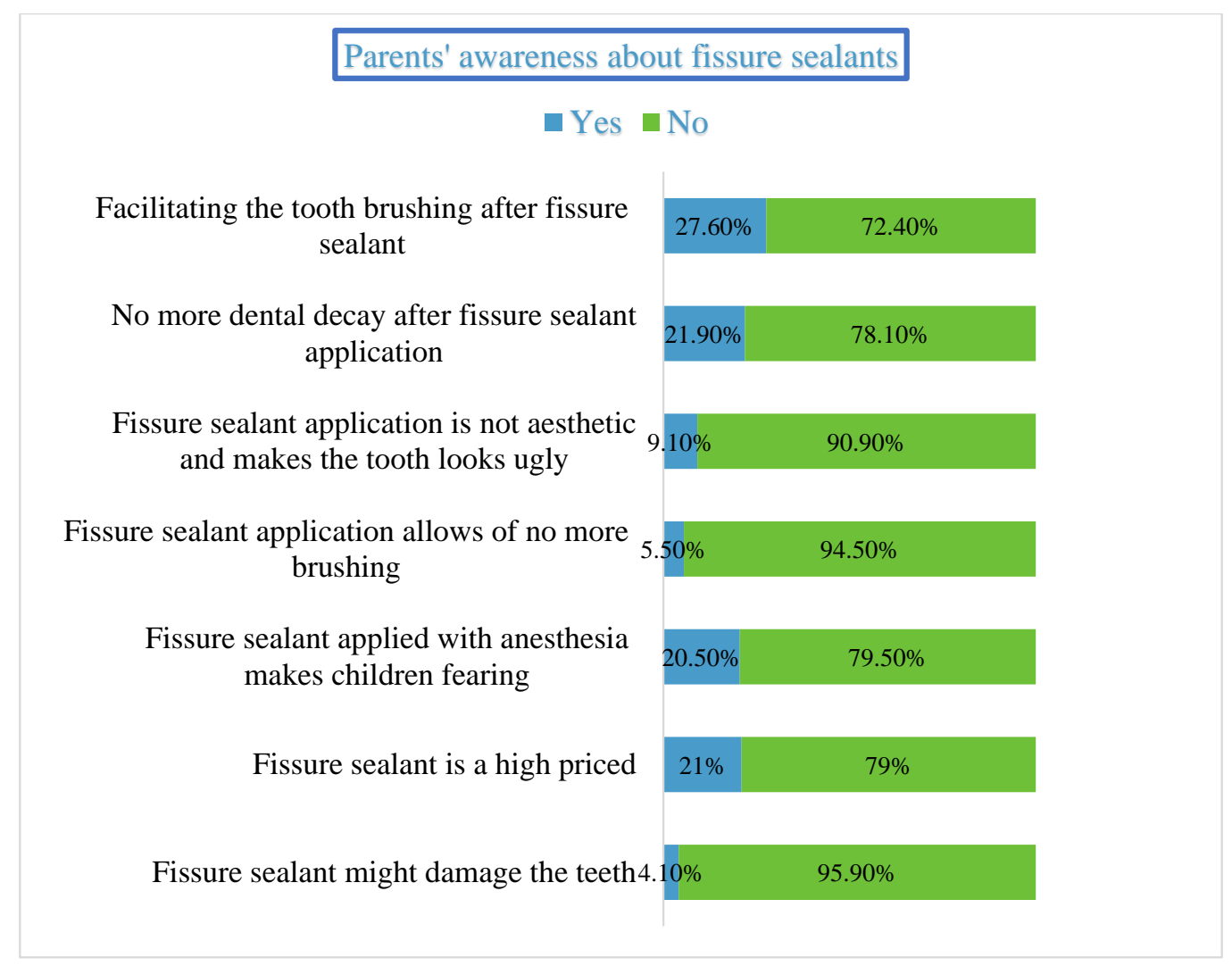

Fig. (3). Awareness of parents about fissure sealants. 
Table 4. Association between sociodemographic factors and fissure sealants among participants.

\begin{tabular}{|c|c|c|c|}
\hline \multirow{2}{*}{\begin{tabular}{|ll} 
& Variables \\
Class year \\
First grade \\
Second grade \\
Third grade \\
Fourth grade \\
\end{tabular}} & \multicolumn{2}{|c|}{$\begin{array}{c}\text { Sealants } \\
\text { Yes N(\%) No N(\%) }\end{array}$} & \multirow{2}{*}{$\begin{array}{c}\text { P-value } \\
0.006\end{array}$} \\
\hline & $\begin{array}{l}4(10.3) \\
12(30.8) \\
15(38.5) \\
8(20.5)\end{array}$ & $\begin{array}{c}122(29.8) 83(20.2) \\
86(21) \\
119(29)\end{array}$ & \\
\hline $\begin{array}{l}\text { Father's education } \\
\text { No school education } \\
\text { School education. } \\
\text { College/University education } \\
\end{array}$ & $\begin{array}{l}14(35.9) \\
25(64.1)\end{array}$ & $\begin{array}{c}5(1.2) \\
176(42.9) \\
229(55.9) \\
\end{array}$ & 0.517 \\
\hline $\begin{array}{l}\text { Mother's education } \\
\text { No school education } \\
\text { School education. } \\
\text { College/University education } \\
\end{array}$ & $\begin{array}{l}16(41) \\
23(59)\end{array}$ & $\begin{array}{c}6(1.5) \\
190(46.3) \\
214(52.2) \\
\end{array}$ & 0.577 \\
\hline $\begin{array}{l}\text { Monthly Family Income } \\
\text { Low: less than 5000 SAR/month } \\
\text { Middle: } 5001-20000 \mathrm{SAR} / \mathrm{month} \\
\text { High: } 20000 \mathrm{SAR} / \mathrm{month} \text { and above }\end{array}$ & $\begin{array}{c}3(8.3) \\
29(80.6) \\
4(11.1) \\
\end{array}$ & $\begin{array}{c}103(26.2) \\
243(61.8) \\
47(12.0) \\
\end{array}$ & 0.047 \\
\hline $\begin{array}{l}\text { Insurance } \\
\text { Yes } \\
\text { No }\end{array}$ & $\begin{array}{l}20(58.8) \\
14(41.2)\end{array}$ & $\begin{array}{l}144(37.9) \\
236(62.1)\end{array}$ & 0.017 \\
\hline
\end{tabular}

\section{DISCUSSION}

This study evaluated caries distribution and fissure sealant utilization in FPMs in female schoolchildren. Our sample found low utilization of fissure sealants, as only $8.7 \%$ of children had fissure sealants in at least one FPM, and only $2.2 \%$ had fissure sealants in four FPMs. In Riyadh, a study on 6-9 years old male children showed that $0.8 \%$ of them had fissure sealant applied to at least one FPM [16]. Another study from Riyadh reported the application of sealant in at least one FPM in $1.3 \%$ of $6-9$ years old female children [15]. In Germany, $55.6 \%$ of $8-12$ years old children had at least one fissure sealant applied [13]. At least one fissure sealant application was reported in $58.8 \%$ of adolescents in Portugal [6]. In Greek, $8.3 \%$ of 12 years old and $8 \%$ of 15 years old children had at least one sealed molar [14]. In our study, a low prevalence of fissure sealants in FPMs may be ascribed to lack of parental awareness about the effectiveness of sealants against caries, low monthly family income, lack of insurance, and inclusion of younger age group participants. In addition, low knowledge of dentists about the use of sealants and never visiting a dentist may also contribute to the under-utilization of sealants $[18,24]$.

More than half of children (55.7\%) in the present study had caries in FPMs. Previous studies have reported caries prevalence of $16.5 \%$ to $66.4 \%$ in FPM $[15,16,25]$. These variations in caries prevalence can be due to differences in oral hygiene behaviors, age and gender of study participants, and methodology in caries measurement. The present study also reported a higher prevalence of caries in mandibular than maxillary FPMs. Similar results were reported in previous studies by Alwayli et al. [15], Aldossary et al. [16], Togoo et al. [25], and Riziwaguli et al. [26]. The difference in the occlusal morphology and earlier eruption of mandibular FPMs compared to maxillary FPMs may account for greater caries attack in mandibular than maxillary FPMs [25].
The literature on caries and fissure sealants in FPMs points to a significantly lower likelihood of caries after the application of fissure sealants (odds ratio $=0.35$ CI 95\% $=0.19-0.65$ ) [6]. There is also evidence about the reduction in DMFS score by $11 \%-24 \%$ with fissure sealants in FPMs [14]. Similar findings were observed in the present study, where participants with fissure sealants in FPMs had significantly lower caries than those without fissure sealants. This is due to the fact that when sealants are applied to the retaining fissures, they serve as physical barriers to block nutrients to microorganisms and thus prevent the formation of biofilm and later caries development [12].

The utilization of fissure sealants increased significantly from first grade to fourth grade in our sample of children, and the highest distribution of sealants was found in third-grade students. This is in agreement with a previous study by Alagili et al., who confirmed a significantly higher prevalence of fissure sealants among older than younger children [27]. This reflects parental attitudes of having sealants in later years of children's tooth eruption. It is also possible that many parents may not even be aware of the age of the eruption of first permanent molars in their children. Caries prevalence in FPMs in children is known to increase with advancing age $[16,26]$. It is also likely that parents take their children to the dentist when they observe caries in their mouth, which becomes more visible in later years, and they end up having sealants to prevent caries. There are reports on lower utilization of dental care in 3-5 years old children (43.7\%) than 6-10 years old children (55.0\%) and 11-15 years old children (57.8\%) [28]. Hence, lower dental attendance in younger children may account for a lower prevalence of sealant in younger children in our study. Nevertheless, two previous similar studies reported no significant difference in the distribution of sealants in children of different grades $[15,16]$.

Socioeconomic inequalities are known to affect the utilization of sealants in children locally and globally [27 - 29]. 
A study conducted in Jeddah, Saudi Arabia, found that children from high-income families were more likely to have sealed teeth than children from middle-income and low-income families [29]. In the U.S, data from the Medical Expenditure Panel Survey and National Health and Nutrition Examination Surveys demonstrated a significant association between the child's family income and the presence of fissure sealants [27, 28]. In line with these studies, our data also revealed that a small percentage of children from low-income families had sealants than middle and high-income families. Income is a good measure of enabling resources for oral care as it improves the ability to pay for dental treatment. Therefore, children from high-income families receive more sealants than children from low-income families [27].

Likewise, insurance coverage improves access to oral care and the likelihood of having sealants. The absence of insurance remains a major barrier to access to fissure sealants. In the present study, a significantly higher proportion of children with insurance had sealants than those without insurance. Similarly, a previous study showed a significant association between having medical insurance and fissure sealants [29]. The Korean National Health and Nutrition Examination Survey (2007-2015) also reported a significant association of insurance coverage with an increased likelihood of dental sealants [30]. The national surveys in the U.S also demonstrated a lower likelihood of receipt of sealants associated with not having insurance [28].

One of the limitations of the study is the inclusion of female schoolchildren only. This is because of the cultural norms in the country which discourage access to male schools by female researchers and vice versa. Data collected from public schools can limit the generalizability of the study findings to the children in private schools. Future studies should include a large sample of both male and female students from public and private schools. Moreover, there are limitations related to the cross-sectional study design, which include under and over-reporting of self-reported data and lack of causal inference. Hence our study data should be used to interpret associations rather than a casualty.

\section{CONCLUSION}

There was a significant association between the application of sealants and caries reduction in FPMs. Dental caries was common in FPMs and was more prevalent in mandibular than maxillary FPMs. A small percentage of children had FPMs filled with sealants which can be attributed to low parental awareness about the effectiveness of sealants against caries. Class year, monthly family income, and insurance were significantly associated with sealant application. Caries prevention programs should raise parental awareness about sealants and encourage their application in children.

\section{ETHICS APPROVAL AND CONSENT TO PARTICIPATE}

Ethical approval of the study was obtained from the Deanship of Scientific Research at Imam Abdulrahman Bin Faisal University, Dammam, Saudi Arabia (IRB 2020-2-068).

\section{HUMAN AND ANIMAL RIGHTS}

No animals were used in this study. All human research procedures were followed in accordance with the ethical standards of the committee responsible for human experimentation (institutional and national) and with the Helsinki Declaration of 1975, as revised in 2013.

\section{CONSENT FOR PUBLICATION}

Informed consent was obtained from parents of school children in the study prior to the oral examination.

\section{AVAILABILITY OF DATA AND MATERIALS}

The data file of this study is available from the corresponding author upon request.

\section{FUNDING}

None.

\section{CONFLICT OF INTEREST}

The authors declare no conflict of interest, financial or otherwise.

\section{ACKNOWLEDGEMENTS}

The authors are grateful to all individuals who facilitated data collection from schools.

\section{REFERENCES}

[1] Kassebaum NJ, Bernabé E, Dahiya M, Bhandari B, Murray CJ, Marcenes W. Global burden of untreated caries: A systematic review and metaregression. J Dent Res 2015; 94(5): 650-8.

[http://dx.doi.org/10.1177/0022034515573272] [PMID: 25740856]

[2] National Institute of Dental, Craniofacial Research (US). Oral health in America: A report of the Surgeon General US Public Health Service, Department of Health and Human Services. 2000.

[3] Martins MT, Sardenberg F, Bendo CB, et al. Dental caries remains as the main oral condition with the greatest impact on children's quality of life. PLoS One 2017; 12(10): e0185365.

[http://dx.doi.org/10.1371/journal.pone.0185365] [PMID: 28981545]

[4] Petersen PE. The World Oral Health Report 2003: Continuous improvement of oral health in the 21 st century--the approach of the WHO Global Oral Health Programme. Community Dent Oral Epidemiol 2003; 31(Suppl. 1): 3-23.

[http://dx.doi.org/10.1046/j..2003.com122.x] [PMID: 15015736]

[5] Marghalani AA, Alsahafi YA, Alshouibi EN. The cost of dental caries in Saudi Arabia. Putting numbers into context. Saudi Med J 2014; 35(1): 93-4.

[PMID: 24445898]

[6] Veiga NJ, Pereira CM, Ferreira PC, Correia IJ. Prevalence of dental caries and fissure sealants in a Portuguese sample of adolescents. PLoS One 2015; 10(3): e0121299.

[http://dx.doi.org/10.1371/journal.pone.0121299] [PMID: 25803849]

[7] Bhardwaj VK. Dental caries prevalence in individual tooth in primary and permanent dentition among 6-12-year-old school children in Shimla, Himachal Pradesh. Int J Health Allied Sci 2014; 3: 125. [http://dx.doi.org/10.4103/2278-344X.132700]

[8] Nazir MA, Bakhurji E, Gaffar BO, Al-Ansari A, Al-Khalifa KS. First permanent molar caries and its association with carious lesions in other permanent teeth. J Clin Diagn Res 2019; 13.

[9] Cvikl B, Moritz A, Bekes K. Pit and fissure sealants-a comprehensive review. Dent J 2018; 6(2): 18

[http://dx.doi.org/10.3390/dj6020018] [PMID: 29895726]

[10] Wright JT, Tampi MP, Graham L, et al. Sealants for preventing and arresting pit-and-fissure occlusal caries in primary and permanent molars. Pediatr Dent 2016; 38(4): 282-308.

[http://dx.doi.org/10.1016/j.adaj.2016.06.003] [PMID: 27557916]

[11] Ahovuo-Saloranta A, Forss H, Walsh T, Nordblad A, Mäkelä M, 
Worthington HV. Pit and fissure sealants for preventing dental decay in permanent teeth. Cochrane Database Syst Rev 2017; 7: CD001830. [http://dx.doi.org/10.1002/14651858.CD001830.pub5] [PMID: 28759120]

[12] Splieth CH, Ekstrand KR, Alkilzy M, et al. Sealants in dentistry: Outcomes of the ORCA saturday afternoon symposium 2007. Caries Res 2010; 44(1): 3-13.

[http://dx.doi.org/10.1159/000271591] [PMID: 20068302]

[13] Klemme B, Tramini P, Niekusch U, Rossbach R, Schulte AG. Relationship between caries prevalence and fissure sealants among 12year-old German children at three educational strata. Soz Praventivmed 2004; 49(5): 344-51.

[http://dx.doi.org/10.1007/s00038-004-3090-2] [PMID: 15497654]

[14] Oulis CJ, Berdouses ED, Mamai-Homata E, Polychronopoulou A. Prevalence of sealants in relation to dental caries on the permanent molars of 12 and 15-year-old Greek adolescents. A national pathfinder survey. BMC Public Health 2011; 11: 100.

[http://dx.doi.org/10.1186/1471-2458-11-100] [PMID: 21320343]

[15] Alwayli HM, Alshiha SA, Alfraih YK, Hattan MA, Alamri AA, Aldossary MS. A survey of fissure sealants and dental caries prevalence in the first permanent molars among primary school girls in Riyadh, Saudi Arabia. Eur J Dent 2017; 11(4): 455-60.

[http://dx.doi.org/10.4103/ejd.ejd 189 17] [PMID: 29279670]

[16] S Aldossary M, A Alamri A, A Alshiha S, A Hattan M, K Alfraih Y, M Alwayli H. Prevalence of dental caries and fissure sealants in the first permanent molars among male children in riyadh, Kingdom of Saudi Arabia. Int J Clin Pediatr Dent 2018; 11(5): 365-70. [http://dx.doi.org/10.5005/jp-journals-10005-1541] [PMID: 30787547]

[17] Tellez M, Gray SL, Gray S, Lim S, Ismail AI. Sealants and dental caries: Dentists' perspectives on evidence-based recommendations. J Am Dent Assoc 2011; 142(9): 1033-40.

[http://dx.doi.org/10.14219/jada.archive.2011.0324] [PMID: 21881070]

[18] Michalaki M, Sifakaki M, Oulis CJ, Lygidakis NA. Attitudes, knowledge and utilization of fissure sealants among Greek dentists: A national survey. Eur Arch Paediatr Dent 2010; 11(6): 287-93. [http://dx.doi.org/10.1007/BF03262765] [PMID: 21108920]

[19] Tahani B, Yadegarfar G, Ahmadi A. Knowledge, attitude, and practice of parents of 7-12-year-old children regarding fissure sealant therapy and professional fluoride therapy. J Educ Health Promot 2017; 6: 106. [http://dx.doi.org/10.4103/jehp.jehp_17_17] [PMID: 29296607]

[20] AL Shalan T. Saudi parents knowledge of and attitude toward the prevention of dental caries. SID J 2003; 15: 27-32.

[21] World health organization. Oral health surveys: basic methods. World
Health Organization. 2013. Available from: https://www.who.int/publications/i/item/9789241548649

[22] Baradaran Nakhjavani Y, Forutan S, Baradaran Nakhjavani F. Mothers' knowledge about fluoride therapy and fissure sealants. J Oral Health Oral Epidemiol 2015.

[23] Jafari A, Soltani MA, Golestan B, Bahrami N. Evaluation of knowledge, attitude and practice of students' parents about fissure sealant therapy. J Dent Med 2010; 23: 242-8.

[24] AlHumaid J, El Tantawi M, AlAgl A, Kayal S, Al Suwaiyan Z, AlAnsari A. Dental visit patterns and oral health outcomes in Saudi children. Saudi J Med Med Sci 2018; 6(2): 89-94.

[http://dx.doi.org/10.4103/sjmms.sjmms_103_17] [PMID: 30787827]

[25] Togoo RA, Yaseen SM, Zakirulla M, Al Garni F, Khoraj AL, Meer A. Prevalence of first permanent molar caries among 7-10 years old school going boys in Abha City, Saudi Arabia. J Int Oral Health 2011; 3: 29-34.

[26] Riziwaguli A, Asiya Y, Liu Y, Yang R, Zou J. Caries prevalence of the first permanent molar among 7-9 years old Uygur children in Urumqi, Xinjiang autonomous region. Shanghai Kou Qiang Yi Xue 2013; 22(5): 559-61

[PMID: 24233210]

[27] Al Agili DE, Griffin SO. Effect of family income on the relationship between parental education and sealant prevalence, national health and nutrition examination survey, 2005-2010. Prev Chronic Dis 2015; 12: E138.

[http://dx.doi.org/10.5888/pcd12.150037] [PMID: 26312383]

[28] Griffin SO, Barker LK, Wei L, Li CH, Albuquerque MS, Gooch BF. Centers for Disease Control and Prevention (CDC). Use of dental care and effective preventive services in preventing tooth decay among U.S. children and adolescents-medical expenditure panel survey, United States, 2003-2009 and national health and nutrition examination survey, United States, 2005-2010. MMWR Suppl 2014; 63(2): 54-60 [PMID: 25208259]

[29] Al Agili DE, Niazy HA, Pass MA. Prevalence and socioeconomic determinants of dental sealant use among schoolchildren in Saudi Arabia. East Mediterr Health J 2012; 18(12): 1209-16.

[http://dx.doi.org/10.26719/2012.18.12.1209] [PMID: 23301395]

[30] Sohn M, Park S, Lim S, Park HJ. Children's dental sealant use and caries prevalence affected by national health insurance policy change: Evidence from the korean national health and nutrition examination survey (2007-2015). Int J Environ Res Public Health 2019; 16(15): 2773.

[http://dx.doi.org/10.3390/ijerph16152773] [PMID: 31382547]

\section{C) 2021 Albaeejan et al.}

This is an open access article distributed under the terms of the Creative Commons Attribution 4.0 International Public License (CC-BY 4.0), a copy of which is available at: (https://creativecommons.org/licenses/by/4.0/legalcode). This license permits unrestricted use, distribution, and reproduction in any medium, provided the original author and source are credited. 